\title{
Gelling properties of hake muscle with addition of freeze-thawed and freeze-dried soy
} phosphatidylcholine liposomes protected with trehalose

(3)

(1)

5

(1)

*Author for correspondence: $\underline{\text { mc.gomez@csic.es }}$

ICTAN-CSIC has implemented and maintains a Quality Management System which fulfils the requirements of ISO standard 9001:2015.

\section{Abstract}

Soy phosphatidylcholine liposomes made with addition of trehalose as cryoprotectant were subjected to freeze-thawing and freeze-drying treatments, and subsequently incorporated in salt-ground hake (M. merluccius) muscle to study their effects on protein aggregation, water binding and thermal gelation. Both liposomal preparations presented similar particle size $(\approx 215$ $\mathrm{nm}$, expressed as z-average) and strong electronegative zeta potential ( $-46 \mathrm{mV})$. The addition of both types of liposomal preparations led to more water trapped within the myofibrillar protein in the salt-ground muscle, as observed by water holding capacity (WHC) and low field nuclear magnetic resonance (LF-NMR). However, the liposomes interfered strongly with the thermal gelation ability of the muscle protein. Differential scanning calorimetry (DSC) analysis of the salt-ground muscle showed that the liposomes caused an increase in the main transition temperature associated with the actin molecule, with a concomitant reduction in total enthalpy change. The hydration state of the trehalose-containing liposomes did not play a significant role in textural properties of the resulting gels. The detrimental role of liposomes in the texture of fish gels should be considered in the design of functional fish products. 
Keywords: hake muscle, liposomes, trehalose, water binding, thermal gelation.

\section{Introduction}

European hake is a highly appreciated fish species commonly consumed in the form of fresh or frozen fillets. However, the muscle protein of this species presents an excellent gel-forming capacity, so it could also be used to obtain healthy products with high added value by incorporating specific nutrients and bioactive compounds (Moreno, Borderías, \& Barón, 2010; Martelo-Vidal, Guerra-Rodríguez, Pita-Calvo, \& Vázquez, 2016). Liposomes, which are typically spherical lipid vesicles consisting of one or more phospholipid bilayers, can be used as delivery carriers for both lipophilic and hydrophilic bioactive compounds, owing to their amphiphilic structure and composition. Encapsulation in liposomes protects bioactive compounds from interaction with other food matrix components and provides enhanced stability against chemical or physical degradation (Da Silva Malheiros, Daroit, \& Brandelli, 2010). The use of non-synthetic soy lecithin or partially purified phosphatidylcholine for food-grade liposome production provides extra nutritional value, owing to the high polyunsaturated fatty acid composition and residual tocopherol content (Taladrid et al., 2017). Liposomes are normally present in the form of aqueous liposomal suspensions, which can be destabilized over time by hydrolysis, oxidation or sedimentation (Sharma \& Sharma, 1997). Various treatments could be applied to improve their stability, such as freezing (Chen, Han, Cai, \& Tang, 2010) or freezedrying (Sebaaly, Greige-Gerges, Stainmesse, Fessi, \& Charcosset, 2016). However, both processes result in the formation of large vesicle aggregates by fusion between neighbouring bilayers. Cryoprotectants, such as carbohydrates or polyalcohols, have been widely used in the preparation of liposomes to improve vesicle stability and to avoid particle aggregation and sedimentation by damage of liposomal membranes during freezing and freeze-drying procedures (Stark, Pabst, \& Prassl, 2010; Wolkers, Oldenhof, \& Glasmacher, 2010). In particular, trehalose has been reported to be an effective liposomal lyoprotectant according to 
the main proposed mechanisms of water replacement and vitrification, although its

51 contribution to kosmotropic and osmotic dehydration effects should not be disregarded (Chen et al., 2010). The amount of cryoprotectant, freezing and lyophilization conditions, and lipid composition are important factors determining the final vesicle size (Arshinova, Sanarova, Lantsova, \& Oborotova, 2012). The physico-chemical and structural properties of liposomes and their hydration state could be important factors determining their suitability as functional ingredients in restructured fish products, since they may influence the interaction with the matrix protein component. In a previous work, freeze-dried soy phosphatidylcholine liposomes loaded with various antioxidant compounds were found to reduce the gel strength of surimi squid gels and to maintain their stability during long-term frozen storage (Marín, Alemán, Sánchez-Faure, Montero, \& Gómez-Guillén 2018).

The aim of this work was to evaluate the effect of adding trehalose-containing soy phosphatidylcholine liposomes that had previously been subjected to freeze-thawing or freeze-drying on the water-binding, protein aggregation and gelling properties of salt-ground hake muscle.

\section{Materials and Methods}

\subsection{Preparation of liposomes}

Partially purified phosphatidylcholine (PC) was obtained by dissolving soybean lecithin in ethyl acetate $(1: 5, \mathrm{w} / \mathrm{v})$ and subsequently performing five washes with acetone (Taladrid et al., 2017). Liposome suspension in $0.2 \mathrm{M}$ phosphate buffer $(\mathrm{pH} 7)$ was prepared according to Marín et al. (2018). Trehalose was added in a proportion of $0.6 \mathrm{~g}$ per $\mathrm{g}$ of PC, according to previous work using glycerol as lyoprotectant (Taladrid et al., 2017; Marín et al., 2018). All 
sonicated (probe-tip) at a measured power of $120 \mathrm{~W}$ for 5 minutes, with a $60 \mathrm{~s}$ stop every min to avoid sample overheating.

\subsection{Stabilization of liposomes}

Fresh liposomal suspension was used as a control sample (L). Freeze-thawed liposomes containing trehalose (FT-T) were obtained by freezing the fresh liposomal suspension at $-20^{\circ} \mathrm{C}$ for $24 \mathrm{~h}$, and then they were thawed and stored at $4{ }^{\circ} \mathrm{C}$ until use (1-2 days). The freeze-drying process was performed by placing $50 \mathrm{~mL}$ of the fresh liposomal suspension in $100 \mathrm{~mL}$ plastic cups with perforated caps, which were frozen at $-80^{\circ} \mathrm{C}$ for $24 \mathrm{~h}$. Lyophilization took place in a VirTis Freeze Drying unit (VirTis BenchTop 6KB, coupled to a TRIVAC-E2 pump) operating at a vacuum level of 0.13 mbar, with the collector starting at a temperature of $-45^{\circ} \mathrm{C}$ and reaching $-80^{\circ} \mathrm{C}$ after $48 \mathrm{~h}$. A fine powder was obtained after freeze-drying (FD-T).

\subsection{Characterization of liposomes}

Particle size (expressed as z-average in \% intensity), polydispersity index (PDI) and zeta potential of the liposomes were determined using a Zetasizer Nano ZS (Malvern Instruments Ltd., Worcestershire, UK). Samples were diluted in $0.2 \mathrm{M}$ phosphate buffer at $\mathrm{pH} 7.0$ to avoid particle aggregation. At least 10 replicates were measured per sample. Dried liposomes were previously rehydrated by suspending in distilled water under magnetic stirring at a concentration of $0.77 \mathrm{mg} / \mathrm{mL}$ for $30 \mathrm{~min}$ at $20^{\circ} \mathrm{C}$.

The moisture content and water solubility of the liposomes were determined as described in a previous work (Marín et al., 2018).

\subsection{Preparation of salt-ground muscle systems and gels}

The FT-T liposomal suspension was previously concentrated (final volume representing $83 \%$ of the original one) by centrifugation at $4000 \mathrm{~g}$ for $1 \mathrm{~h}$ at $2{ }^{\circ} \mathrm{C}$ (Multifuge $3 \mathrm{~L}-\mathrm{R}$, Heraeus, Madrid, 
Spain) using centrifugal filters (Amicon ${ }^{\circledast}$ Ultra-15, Ultrace ${ }^{\circledR}-3 \mathrm{~K}$, Merck Millipore Ltd., Tullagreen, Carrigtwohill, County Cork, Ireland). European hake (M. merluccius) fillets were purchased in a local market. Chopped muscle (150 g) was homogenized with $1 \% \mathrm{NaCl}$ and 75 $\mathrm{mL}$ of the concentrated liposomal suspension (FT-T) in a beater surrounded by ice for $2 \mathrm{~min}$. On the other hand, $150 \mathrm{~g}$ of chopped muscle was also homogenized with $1 \% \mathrm{NaCl}$ and with 6.4 $\mathrm{g}$ of freeze-dried liposomes (FD-T) in a beater for $1 \mathrm{~min}$; then distilled water was added to complete a liposomal volume of $75 \mathrm{~mL}$ and it was beaten again for $3 \mathrm{~min}$. Additional water was incorporated in order to adjust the final moisture content in the salt-ground muscle so that both wet and dried liposomal preparations represented the same dry weight in the muscle formulation. A control salt-ground muscle batch (150 g) without liposomes (M) was prepared by adding $75 \mathrm{~mL}$ of water to the formulation. The salt-ground muscle systems were stored at 4 ${ }^{\circ} \mathrm{C}$ until use.

The gels were prepared by stuffing the resulting pastes into $35 \mathrm{~mm}$ plastic cellulose casings (Viscase S.A., Bagnold Cedex, France), and heating in a Rational oven (Combi-Master CM 6) at $60{ }^{\circ} \mathrm{C}$ for $45 \mathrm{~min}$. After thermal treatment, the gels were dipped into ice water to cool them quickly and stored overnight at $4{ }^{\circ} \mathrm{C}$.

\subsection{Characterization of salt-ground muscle systems}

\subsubsection{Water content, protein solubility and water holding capacity}

Moisture content was determined according to method 950.46 (A.O.A.C., 2005). Protein solubility in $5 \% \mathrm{NaCl}$ solution was determined according to Marín et al. (2018), and was expressed as soluble protein with respect to total protein in the hake muscle. The water holding capacity (WHC) was determined using the centrifugation method described by GómezGuillén, Montero, Hurtado and Borderías (2000). Determinations were carried out at least in triplicate.

\subsubsection{SDS-polyacrylamide gel electrophoresis (SDS-PAGE)}


122 The electrophoresis of soluble protein was performed using polyacrylamide gels (10\% Mini-

123 PROTEAN ${ }^{\circledR}$ TGXTM Precast Protein Gels, 12-well, $20 \mu \mathrm{L}$ ) from Bio-Rad (Bio-Rad Laboratories,

124 S.A., Madrid, Spain). The samples were mixed in a proportion of 1:1 with the loading buffer (50

$125 \mathrm{mM}$ TRIS-HCL (pH 6.8), 10\% $\beta$-mercaptoethanol, 2 mM EDTA, $0.1 \%$ bromophenol blue, 5\% SDS

126 and $30 \%$ glycerol). Protein samples $(\approx 2.5 \mathrm{mg} / \mathrm{mL})$ were heated at $90{ }^{\circ} \mathrm{C}$ for $5 \mathrm{~min}$ and $15 \mu \mathrm{l}$ was

127 loaded. A molecular weight standard (Precision Plus Protein ${ }^{\mathrm{TM}}$ All Blue Prestained Protein Standards) from Bio-Rad was used.

\subsubsection{Particle size of soluble protein aggregates}

Particle size (\% in intensity) measurement of the salt-ground muscle soluble protein was performed by dynamic light scattering using the Zetasizer Nano ZS (Malvern Instruments Ltd., Worcestershire, UK) at $5{ }^{\circ} \mathrm{C}$. An aliquot of each soluble protein fraction was previously diluted 1000 -fold with $0.2 \mathrm{M}$ phosphate buffer $(\mathrm{pH} 7)$ and 10 replicates per sample were measured.

\subsubsection{Low-Field Nuclear Magnetic Resonance}

Relaxometry analysis was carried out according to Sánchez-Alonso, Moreno and Careche (2014), using a Low-Field Nuclear Magnetic Resonance Minispec mq20 analyser (Bruker Optik $\mathrm{GmbH}$, Germany) with a magnetic field strength of $0.47 \mathrm{~T}$ (proton resonance frequency of 20 $\mathrm{MHz})$. A weighted amount of $\approx 2 \mathrm{~g}$ salt-ground muscle $(1 \times 1 \times 2 \mathrm{~cm})$ was placed in NMR tubes $(1.8$ $\mathrm{cm}$ diameter and $18 \mathrm{~cm}$ height). Sample temperature was kept at $4{ }^{\circ} \mathrm{C}$ using a Thermo Haake ${ }^{\circledR}$ C/DC class DC10-K10 refrigerated circulator (Fisher Scientific S.L., Madrid, Spain). Transverse relaxation data $\left(T_{2}\right)$ were measured using the Carr-Purcell Meiboom-Gill pulse sequence with a t-value of $150 \mu \mathrm{s}$, and 16 scans at $2 \mathrm{~s}$ intervals with a total of 3000 echoes were obtained per sample. Relaxation time distribution was analysed using the CONTIN regularization algorithm. At least four replicates were measured per sample.

\subsubsection{Dynamic oscillatory rheology}


Viscoelastic properties of the salt-ground muscle systems (elastic modulus $\mathrm{G}^{\prime}$, viscous modulus

$147 \mathrm{G}^{\prime \prime}$ and phase angle $\delta$ ) were determined using a Bohlin rheometer (Bohlin Instruments Ltd., model CVO, Worcestershire, UK) with a cone-plate geometry (cone angle $4^{\circ}$, gap $=0.15 \mathrm{~mm}$ ). A dynamic frequency sweep was performed at $10^{\circ} \mathrm{C}$ by applying oscillation amplitude within the linear region $(\gamma=0.005)$ over the frequency range $0.1-10 \mathrm{~Hz}$. The dynamic temperature sweep was done by heating from $15{ }^{\circ} \mathrm{C}$ to $80{ }^{\circ} \mathrm{C}$ at a scan rate of $1{ }^{\circ} \mathrm{C} / \mathrm{min}$, frequency of $1 \mathrm{~Hz}$ and target strain $\gamma=0.005$. Results were the mean of at least 2 determinations.

\subsection{Gel strength}

A puncture test was performed on heat-induced gels using a TA-XT Plus Texture Analyser (Texture Technologies Corp., Scarsdale, NY, USA) with a cylindrical stainless steel plunger (5 $\mathrm{mm}$ diameter) attached to a $5 \mathrm{~kg}$ load cell, at a speed of $0.33 \mathrm{~mm} / \mathrm{s}$ and $90 \%$ strain. The breaking force (in $\mathrm{N}$ ) and breaking deformation (in $\mathrm{mm}$ ) were determined. The gel strength $(\mathrm{N} \cdot \mathrm{mm})$ was the product of multiplying the breaking force by the breaking deformation. Results were the average of three determinations.

\subsection{Statistical analysis}

Analysis of variance was performed using the SPSS ${ }^{\circledR}$ computer program (IBM SPSS Statistics 22 Software, Inc., Chicago, IL, USA). Differences between means were assessed on the basis of confidence intervals using the Tukey test, with a significance level set at $p \leq 0.05$.

\section{Results and Discussion}

\subsection{Liposome properties} The particle size, polydispersity (PDI) and zeta potential of freeze-thawed and freeze-driedrehydrated liposomes, both made with addition of trehalose (FT-T and FD-T), are shown in 
Table 1. For comparison purposes, the properties of freshly prepared liposomes (without

170 trehalose) are also shown. Despite the use of the cryoprotectant, freezing and subsequent

171 thawing (FT-T liposomes) induced a significant increase in particle size and PDI; however, no change ( $p>0.05)$ was found in zeta potential with respect to the fresh liposomal suspension (L), indicating that vesicle stability was maintained. In a preliminary work without trehalose, the effect of freezing and subsequent thawing was found to increase the z-average of liposomes by up to $507 \mathrm{~nm}$ (data not shown), which was much higher than in the present liposomes. The freeze-dried liposomes (FD-T) showed no significant changes ( $p>0.05)$ with respect to the frozen-thawed liposomes (FT-T). Thus, in the present study trehalose seemed to play the same role in both types of liposome. According to Ohtake, Schebor and de Pablo (2006), the trehalose-phospholipid interaction and its distribution across the liposomal membrane were similar in both freeze-dried and fully hydrated samples. Wolkers et al. (2010) proposed that the protective role of trehalose in dehydrated liposomes was to control the rate of water loss and to trap water around phospholipid head groups during the initial phase of drying. In synthetic dipalmitoylphosphatidylcholine (DPPC) vesicles, no increase in particle size induced by freezing or freeze-drying was observed in the presence of trehalose (Ohtake et al., 2006). In the present work, the moderate increase in particle size could be due to insufficient concentration of trehalose or uneven distribution across the membrane (Ohtake et al., 2006; Christensen et al., 2007).

The freeze-dried preparation (FD-T) had the appearance of a fine powder, with residual moisture content of $1.53 \%$ (Table 1). Both FT-T and FD-T samples presented similar ( $p>0.05$ ) water solubility $(\approx 96 \%)$, slightly lower than in the fresh preparation. This finding indicated that vesicle aggregation induced by freezing or freeze-drying was relatively low, despite the increase in particle size.

\subsection{Characterization of salt-ground muscle systems}


195

196

197

198

The moisture content, protein solubility and water holding capacity (WHC) of the salt-ground muscle with and without added liposomes are shown in Table 2. The moisture content in the two samples with added liposomes was similar, and slightly lower than in the control batch (M). The soluble protein in the salt-ground muscle was significantly decreased $(p \leq 0.05)$ by the addition of liposomes (Table 2). Being a highly water-soluble powder, the FD-T preparation reduced the myofibrillar protein solubility to a greater extent $(p \leq 0.05)$ than the FT-T suspension. By adding the liposomes in the dry state, they might have established more competition with the myofibrillar protein for the water molecules, causing more protein dehydration and aggregation. These results indicated that the addition of liposomes to the salt-ground muscle increased the state of aggregation of the myofibrillar protein.

The water holding capacity (WHC) was considerably higher $(p \leq 0.05)$ in the liposome-containing samples than in the control batch (Table 2). Water released in the control batch was higher than the water that was introduced in the formula, indicative of intrinsic water that was not properly bound to the muscle protein. A possible explanation was that water molecules bound to the polar head groups at the liposome membrane surface could increase the overall hydration state of the surrounding myofibrillar protein. This effect did not depend on the initial hydration state of the liposomal preparation, since no significant differences $(p>0.05)$ were found between FT-T and FD-T batches.

\subsubsection{SDS-PAGE of soluble protein}

The soluble protein electrophoretic profile of the muscle systems with or without liposomes is shown in Fig. 1. The molecular weight pattern in all batches was characterized by the practical absence of the band at $\approx 200 \mathrm{kDa}$, assigned to myosin heavy chain (MHC). In contrast, two prominent bands close to $37 \mathrm{kDa}$, associated with the presence of troponin and tropomyosin, were observable in the three samples. Another thinner band appearing at a molecular weight 
slightly lower than $50 \mathrm{kDa}$ was tentatively assigned to remaining partially soluble actin. The intensity of these main protein bands showed a slight tendency to decrease in the presence of liposomes, especially with the FD-T preparation. No large protein aggregates at the top of the stacking gel were present in any of the samples studied. These results were in agreement with the low protein solubility reported in Table 2 , being indicative of the relatively high degree of protein crosslinking causing the main myofibrillar proteins ( $\mathrm{MHC}$ and actin) to remain in the insoluble fraction, even in the case of the control $(\mathrm{M})$ batch. These results indicated that the functional quality of the hake muscle used in the present study was not high, and that the differences in soluble protein of the different batches seem to be more quantitative than qualitative. The addition of liposomes, especially when added in the dry state, contributed to an increase in protein aggregation, but they did not change the protein electrophoretic mobility, so no evident signs of covalent protein-lipid interactions taking part of the soluble protein aggregates could be deduced. The lower protein solubility found in the liposomecontaining batches could be mostly attributed to non-covalent interactions, probably hydrogen bonding between protein side chains and liposome membrane polar head groups or attached water molecules.

\subsubsection{Size of soluble protein aggregates}

Dynamic light scattering (DLS) was used to gain an insight into the particle size distribution of the salt-soluble protein aggregates in the various muscle systems (Fig. 2), which could not be evidenced by the electrophoretic study. The soluble protein of the three muscle systems showed similar bimodal particle size distributions. The predominant protein aggregate population peaked in the range between $494 \mathrm{~nm}$ for the $\mathrm{M}$ batch and $596 \mathrm{~nm}$ for the FT-T batch. A low contribution of smaller protein fragments was found to peak between 159 and $182 \mathrm{~nm}$. The FT-T liposomes caused a higher shift to increased particle size than the FD-T preparation in both protein populations. However, the noticeable reduction in the intensity of 
244 the peak associated with the lower molecular weight peptide fraction in the FD-T batch

245 suggested a considerable decrease in the presence of these small fragments, which had 246 probably become part of larger protein aggregates that could have remained in the insoluble 247 protein fraction. This finding would be consistent with the slightly lower protein solubility 248 (Table 2) and reduced protein band intensities (Fig. 1) found in the FD-T batch.

\section{3.2.4. Differential scanning calorimetry (DSC)}

250 The thermal properties of the three muscle systems with and without liposomes are shown in Fig. 3. The DSC trace of the control muscle system (M) showed a main endothermic transition occurring at $69.4{ }^{\circ} \mathrm{C}$, which could be associated with thermal denaturation of F-actin. Two other minor transitions, hardly visible at onset temperatures of $42.0^{\circ} \mathrm{C}$ and $29.2{ }^{\circ} \mathrm{C}$, were assigned to the myosin rod and myosin subfragment S1, respectively. The transitions observed in the myosin molecule were diffused because the protein was partially denatured as a result of muscle homogenization and salt-blending (Fernández-Martín, Pérez-Mateos, \& Montero, 1998). F-actin was more resistant to salt-induced denaturation than myosin, as deduced from the more pronounced endothermic event. The addition of liposomes to the salt-ground muscle caused an increase in the main transition temperature associated with the actin molecule, with a concomitant reduction in total enthalpy change. Furthermore, the traces in the thermal regions associated with the myosin molecule became even more diffuse in the presence of liposomes. These findings indicated noticeable structural changes in the myofibrillar protein, probably caused by interaction with the liposomes.

The type of liposome preparation did not appear to produce any great differential change in denatured myosin thermal behaviour. In contrast, the increase in thermal stability of F-actin as a result of liposome addition was higher when liposomes were added in the dry state (FD-T). This batch was characterized by a higher degree of protein aggregation, as shown by the lower percentage of salt-soluble protein and lower amount of small protein fragments remaining in 

salt-grinding.

\subsubsection{LF-NMR- ${ }^{1} \mathrm{H}$ analysis}

Differences in water distribution (by chemical proton exchange) that might be associated with protein denaturation and aggregation were evaluated by Low Field NMR (Erikson, Standal, Aursand, Veliyulin, \& Aursand, 2012). Fig. 4 shows the transversal proton relaxation time curves in the various salt-ground muscle systems. The main relaxation component $\left(T_{21}\right)$, which represented water located within highly organized protein structures, peaked at $85 \mathrm{~ms}$ in the $\mathrm{M}$ and FT-T batches, and at $88 \mathrm{~ms}$ in the FD-T batch. Considerably shorter relaxation times were reported for the $T_{21}$ water population in either frozen or unfrozen hake muscle (SánchezAlonso et al., 2014). This difference could be attributed to an increased relaxation time of water in the intramyofibrillar space owing to salt-induced protein unfolding, causing the protein network to expand. A slower relaxation component ( $T_{22}$ at $491 \mathrm{~ms}$ ) was clearly visible in the control muscle system without liposomes, and corresponded to extra-myofibrillar water that could be lost as drip. The $\mathrm{T}_{22}$ component was reported to appear in hake muscle as an extra band in the range of $120-360 \mathrm{~ms}$, resulting from morphological protein changes after freezing (Sánchez-Alonso et al., 2014). This relaxation behaviour in the salt-ground muscle indicated chemical exchange between water and protein protons resulting from salt-induced protein denaturation (Hills, Wright, \& Belton, 1989). The addition of liposomes led to a noticeable increase in the $T_{21}$ relaxation amplitude, and a very small proton exchange at the $T_{22}$ relaxation time. These findings strongly suggested that most of the water was trapped within the myofibrillar protein network in the presence of liposomes, and they were consistent with

291 the noticeable increase in water holding capacity resulting from addition of liposomes to the salt-ground muscle. A fast small proton relaxation component $\left(T_{2 b}\right)$ took place at a relaxation time of $2.1 \mathrm{~ms}$ in the control system (M) (Fig. 4 inset). This component has been related to the 
presence of water tightly associated with macromolecules (Erikson et al., 2012). This NMR event apparently shifted towards higher relaxation times in the systems with liposomes (2.7 $\mathrm{ms}$ in FT-T and $3.5 \mathrm{~ms}$ in FD-T), indicative of protein morphological changes, especially in the FD-T batch. The slightly higher amplitude of $\mathrm{T}_{21}$ in the FT-T batch coinciding with higher amplitude in the $T_{2 b}$ component was consistent with higher amount of water closely bound to the protein. A new faster component arising at $1.2 \mathrm{~ms}$ was directly related to the presence of the phospholipid vesicles, since no NMR signal was detected in the control M system.

\subsubsection{Dynamic oscillatory rheology}

The degree of protein aggregation in the presence or absence of liposomes in the salt-ground muscle was also assessed by determining the rheological frequency dependence at $10^{\circ} \mathrm{C}$. In all batches, $G^{\prime}$ prevailed over $G^{\prime \prime}$ throughout the oscillating frequency range studied, indicating a viscoelastic gel-like behaviour (Badii \& Howell, 2002). Table 3 shows the elastic modulus $\left(\mathrm{G}^{\prime}{ }_{1 \mathrm{~Hz}}\right)$, viscous modulus $\left(\mathrm{G}^{\prime \prime}{ }_{1 \mathrm{~Hz}}\right)$ and phase angle determined at $1 \mathrm{~Hz}$, as well as the $\mathrm{n}^{\prime}$ exponent obtained after fitting the mechanical spectra of $G^{\prime}$ to the power law model $\left(R^{2}>0.99\right)$. The addition of liposomes tended to increase both $\mathrm{G}^{\prime}$ and $\mathrm{G}^{\prime \prime}$ values, more markedly in the case of the FD-T batch. A slight increase $(p \leq 0.05)$ in phase angle was found in the FT-T batch, due to the relatively higher contribution of the viscous component. Furthermore, this batch also presented slightly higher matrix instability against frequency changes, as denoted by the increase in the $n^{\prime}$ value (Campo \& Tovar, 2008). The increases in phase angle and $n^{\prime}$ indicated that liposomes added in the form of an aqueous dispersion (FD-T) might produce slightly higher matrix discontinuity by interfering with protein-protein interactions, probably because they could access the protein side chains more easily than if added in the dry form. The changes in elastic modulus $\left(G^{\prime}\right)$, viscous modulus $\left(G^{\prime \prime}\right)$ and phase angle $(\delta)$ as a function of heating temperature are shown in Fig. 5. The control muscle showed a pronounced drop in 
the breakdown of heat-labile hydrogen bonds. This effect, which was more pronounced in the $M$ batch, promoted protein unfolding and caused greater exposure of reactive sites in the absence of liposomes, which was beneficial to the subsequent formation of intermolecular bonds at higher temperatures. This effect was in agreement with the sharper increase in $\mathrm{G}^{\prime}$ and $\mathrm{G}^{\prime \prime}$ at elevated temperatures in the control batch as compared to both liposomecontaining samples. A relative $\mathrm{G}^{\prime}$ peak, associated with the so-called setting phenomenon, was observed at $\approx 38{ }^{\circ} \mathrm{C}$ in all batches. This peak corresponded to preliminary protein stabilization by hydrophobic interactions and by $\varepsilon$-( $($-glutamyl)-lysine covalent bonds induced by endogenous transglutaminase activity (Lanier, Yongsawatdigul, \& Carvajal-Rondanelli, 2013). The subsequent drop in $\mathrm{G}^{\prime}$ peaking at $45{ }^{\circ} \mathrm{C}$, typical of the modori phenomenon, was also observable in the three batches and was the result of protein network disintegration, probably due to optimum activity of heat-stable proteases. The subsequent rise in $\mathrm{G}^{\prime}$ and coincident decline in phase angle from $\approx 45^{\circ} \mathrm{C}$ to $80^{\circ} \mathrm{C}$ indicated the formation of the gel protein network by thermostable hydrophobic interactions and covalent disulfide bonds. Thermal gelation was found to take place in two steps. From $45{ }^{\circ} \mathrm{C}$ to $60{ }^{\circ} \mathrm{C}$ both $\mathrm{G}^{\prime}$ and $\mathrm{G}^{\prime \prime}$ exhibited a pronounced increase, but at higher temperatures $G^{\prime \prime}$ values declined, indicating that the gel matrix was already formed. The subsequent rise in $\mathrm{G}^{\prime}$ to $80^{\circ} \mathrm{C}$ could be due to gel reinforcement, mostly by strong covalent disulfide bonds. The presence of liposomes did not hinder the effect of the endogenous TGase activity (setting) or the subsequent autolytic protein degradation (modori). When liposomes were added, the thermal aggregation profile resembled that of the control system, but differing essentially in that from $\approx 55^{\circ} \mathrm{C}$ onwards the increase in $\mathrm{G}^{\prime}$ was much more limited. As mentioned above, the presence of liposomes counteracted the extent of intermolecular bond formation by interfering with protein-protein interactions. The higher protein aggregation induced by the addition of liposomes during the muscle grinding step might hinder the availability of protein-reactive sites for subsequent protein thermal gelation.

\subsubsection{Mechanical properties of gels}



presented the highest $(p \leq 0.05)$ gel strength, resulting from having the highest breaking force and deformation. The decrease in gel strength produced by liposome addition was previously reported in squid gels (Marín et al., 2018). The hydration state of the trehalose-containing liposomes did not play a significant role in gel textural properties, since no significant differences ( $p>0.05)$ between the FT-T and FD-T batches were observed. This finding was in agreement with the similar viscoelastic behaviour of the two batches in the temperature sweep test. These results confirmed that the presence of liposomes interfered strongly with the formation of the gel network, leading to weaker gels. Cardoso, Mendes, Saraiva, Vaz-Pires and Nunes (2010) reported higher gel strength for hake mince gels heated at $90{ }^{\circ} \mathrm{C}$ for $1 \mathrm{~h}$, which could be partly due to their lower moisture content ( $80 \%$ vs. $85 \%$ ) and higher proportion of $\mathrm{NaCl}$ used during salt-grinding (2.5\% vs. $1 \%)$. Despite the textural detriment, it has been suggested that the distortion of protein-protein interactions by the presence of liposomes in squid surimi gels enhanced myofibrillar protein digestibility (Marín et al., 2018).

\section{Conclusions}

Soy phosphatidylcholine liposomes stabilized by freezing and freeze-drying, using trehalose as cryo-/lyoprotectant, had similar vesicle properties. Regardless of their hydration state, liposomes increased the water binding of the salt-ground muscle, but they hindered the thermal gelation ability by increasing the aggregation state of the myofibrillar protein. The detrimental role of liposomes in the texture of fish gels should be considered in the design of functional fish products.

\section{Acknowledgements} financial support (projects AGL2014-52825 and AGL2017-84161-C2-1-R). We are grateful to the Analysis Service Unit of ICTAN-CSIC for the DSC analysis. 


\section{References}

372 A.O.A.C. (2005). Official methods of analysis. Gaithersburg, MD, USA: Association of Official 373 Analytical Chemists.

374 Arshinova, O.Y., Sanarova, E.V., Lantsova, A.V., \& Oborotova, N.A. (2012). Drug synthesis 375 methods and manufacturing technology. Pharmaceutical Chemistry Journal, 46(4), 228-233.

376 Badii, F., \& Howell, N.K. (2002). Effect of antioxidants, citrate, and cryoprotectants on protein 377 denaturation and texture of frozen cod (Gadus morhua). Journal of Agricultural and Food 378 Chemistry, 50(7), 2053-2061.

379 Campo, L., \& Tovar, C. (2008). Influence of the starch content in the viscoelastic properties of 380 surimi gels. Journal of Food Engineering, 84(1), 140-147.

381 Cardoso, C.L., Mendes, R.O., Saraiva, J.A., Vaz-Pires, P.R., \&Nunes, M.L. (2010). Quality 382 characteristics of high pressure-induced hake (Merluccius capensis) protein gels with and 383 without MGTase. Journal of Aquatic Food Product Technology, 19, 193-213.

Chen, C., Han, D., Cai, C., \& Tang, X. (2010). An overview of liposome lyophilization and its 385 future potential. Journal of Controlled Release, 142, 299-311.

Christensen, D., Foged, C., Rosenkrands, I., Nielsen, H.M., Andersen, P., Agger, E.M. (2007). Trehalose preserves DDA/TDB liposomes and their adjuvant effect during freeze-drying. Biochimica et Biophysica Acta - Biomembranes, 1768(9), 2120-2129. da Silva Malheiros, P., Daroit, D.J., \& Brandelli, A. (2010). Food applications of liposomeencapsulated antimicrobial peptides. Trends in Food Science and Technology, 21(6), 284-292. 
391

392

393

394

395

396

397

398

399

400

401

402

403

404

405

406

407

408

409

410

411

412

Erikson, U., Standal, I.B., Aursand, I.G., Veliyulin, E., \& Aursand, M. (2012). Use of NMR in fish processing optimization: a review of recent progress. Magnetic Resonance in Chemistry, 50, 471-480.

Fernández-Martín, F., Pérez-Mates, M., \& Montero, P. (1998). Effect of pressure/heat combinations on blue whiting (Micromesistius poutassou) washed mince: thermal and mechanical properties. Journal of Agricultural and Food Chemistry, 46, 3257-3264.

Gómez-Guillén, M.C., Montero, P., Hurtado, O., \& Borderías, A.J. (2000). Biological characteristics affect the quality of farmed Atlantic salmon and smoked muscle. Journal of Food Science, 65, 53-60

Hills, B.P., Wright, K.M., \& Belton, P.S. (1989). N.M.R. studies of water proton relaxation in Sephadex bead suspensions. Molecular Physics, 67(1), 193-208.

Lanier, T.C., Yongsawatdigul, J., \& Carvajal-Rondanelli, P. (2013). Surimi Gelation Chemistry. In J.W. Park (Ed.), Surimi and Surimi Seafood (pp. 101-140). CRC Press. Taylor \& Francis Group.

Marín, D., Alemán, A., Sánchez-Faure, A., Montero, P., \& Gómez-Guillén, M.C. (2018). Freezedried phosphatidylcholine liposomes encapsulating various antioxidant extracts from natural waste as functional ingredients in surimi gels. Food Chemistry, 245, 525-535.

Martelo-Vidal, M.J., Guerra-Rodríguez, E., Pita-Calvo, C., \& Vázquez, M. (2016). Reduced-salt restructured European hake (Merluccius merluccius) obtained using microbial transglutaminase. Innovative Food Science and Emerging Technologies, 38, 182-188.

Moreno, H.M., Javier Borderías, A., \& Baron, C.P. (2010). Evaluation of some physico-chemical properties of restructured trout and hake mince during cold gelation and chilled storage. Food Chemistry, 120, 410-417. 
413 Ohtake, S., Schebor, C., \& de Pablo, J.J. (2006). Effects of trehalose on the phase behavior of 414 DPPC-cholesterol unilamellar vesicles. Biochimica et Biophysica Acta-Biomembranes, 1758(1), $415 \quad 65-73$.

416 Sánchez-Alonso, I., Moreno, P., \& Careche, M. (2014). Low field nuclear magnetic resonance 417 (LF-NMR) relaxometry in hake (Merluccius merluccius, L.) muscle after different freezing and 418 storage conditions. Food Chemistry, 153, 250-257.

Sebaaly, C., Greige-Gerges, H., Stainmesse, S., Fessi, H., \& Charcosset, C. (2016). Effect of composition, hydrogenation of phospholipids and lyophilisation on the characteristics of eugenol-loaded liposomes prepared by the ethanol injection method. Food Bioscience, 15, 110.

Sharma, A., \& Sharma, U.S. (1997). Liposomes in drug delivery: Progress and limitations. International Journal of Pharmaceutics, 154, 123-140.

Stark, B., Pabst, G., \& Prassl, R. (2010). Long-term stability of sterically stabilized liposomes by freezing and freeze-drying: Effects of cryoprotectants on structure. European Journal of Pharmaceutical Sciences, 41(3-4), 546-555. 429 (2017). Effect of chemical composition and sonication procedure on properties of food-grade 430 soy lecithin liposomes with added glycerol. Food Research International, 100, 541-550.

431 Wolkers, W.F., Oldenhof, H., \& Glasmacher, B. (2010). Dehydrating phospholipid vesicles 432 measured in real-time using ATR Fourier transform infrared spectroscopy. Cryobiology, 61(1), 108-114. 
436 FIG. 1. SDS-PAGE of the soluble protein from salt-ground muscle (M) alone and with liposomes: 437 FT-T (Freeze-thawed with trehalose) and FD-T (Freeze-dried with trehalose). MHC=myosin 438 heavy chain; $\mathrm{Tn}=$ troponin; $\mathrm{Tm}=$ tropomyosin.

439 FIG. 2. Size distribution of soluble protein aggregates from salt-ground muscle (M) alone and 440 with liposomes: FT-T (Freeze-thawed with trehalose) and FD-T (Freeze-dried with trehalose).

441 FIG. 3. DSC thermograms of salt-ground muscle (M) alone and with liposomes: FT-T (Freeze442 thawed with trehalose) and FD-T (Freeze-dried with trehalose).

443 FIG. 4. LF-NMR relaxation time distribution of salt-ground muscle (M) alone and with 444 liposomes: FT-T (Freeze-thawed with trehalose) and FD-T (Freeze-dried with trehalose).

445 FIG. 5. Temperature sweep test of salt-ground muscle (M) alone and with liposomes: FT-T 446 (Freeze-thawed with trehalose) and FD-T (Freeze-dried with trehalose).

447 FIG. 6. Puncture test of gels from salt-ground muscle (M) alone and with liposomes: FT-T 448 (Freeze-thawed with trehalose) and FD-T (Freeze-dried with trehalose). BF=breaking force; $449 \quad B D=$ breaking deformation; GS=gel strength. 


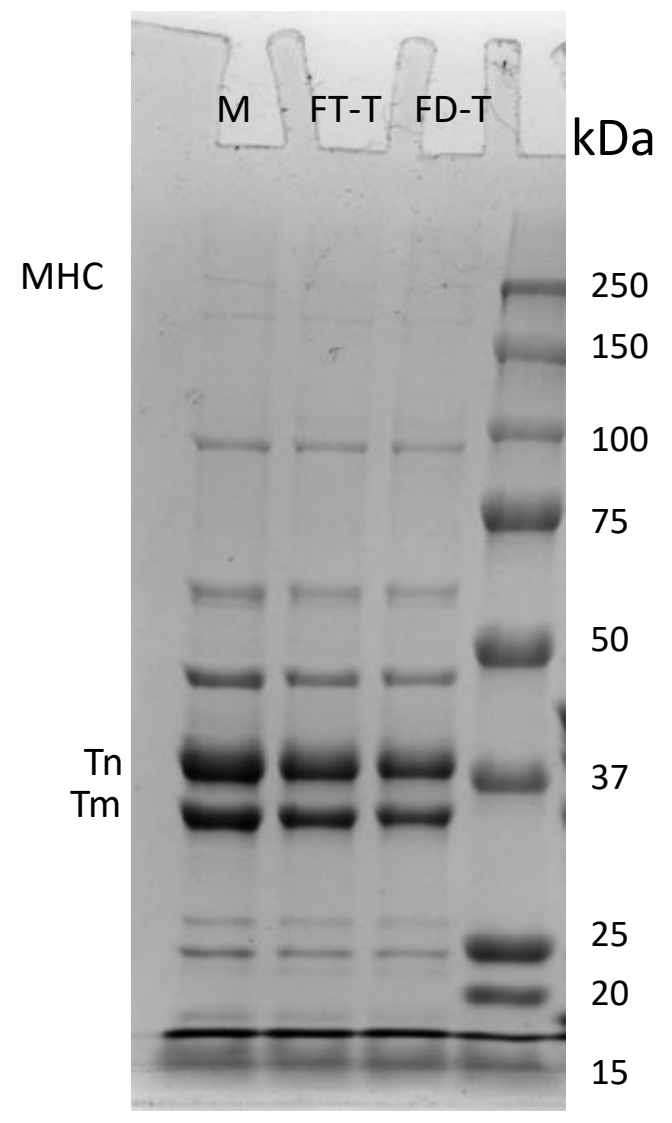

Figure 1 


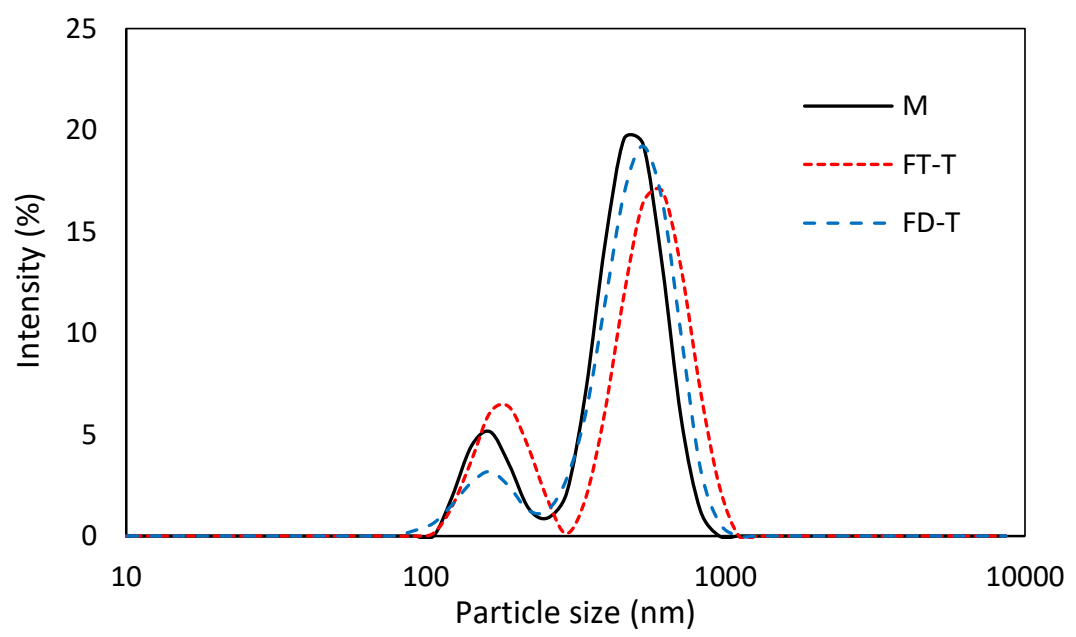

Figure 2 


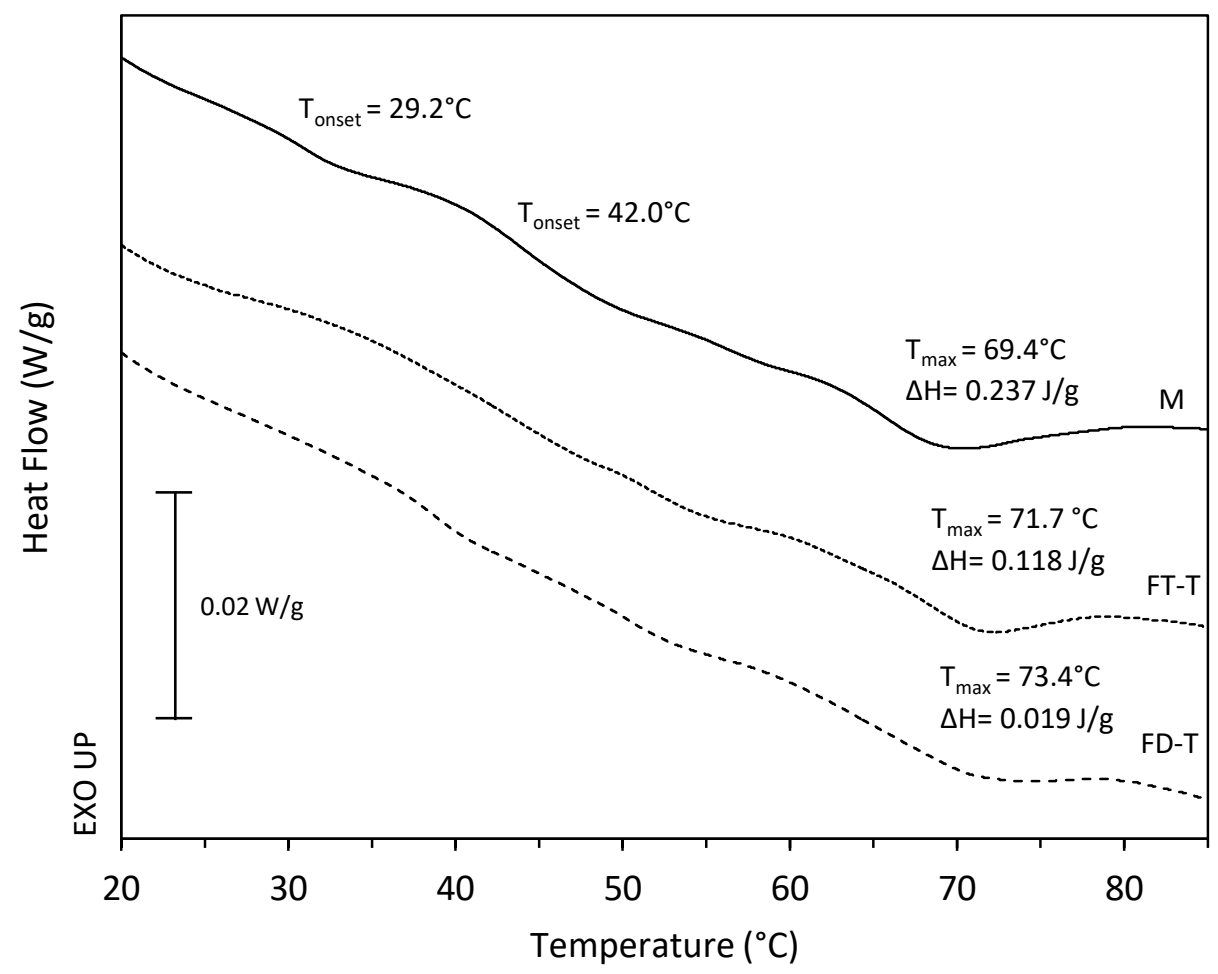

Figure 3 


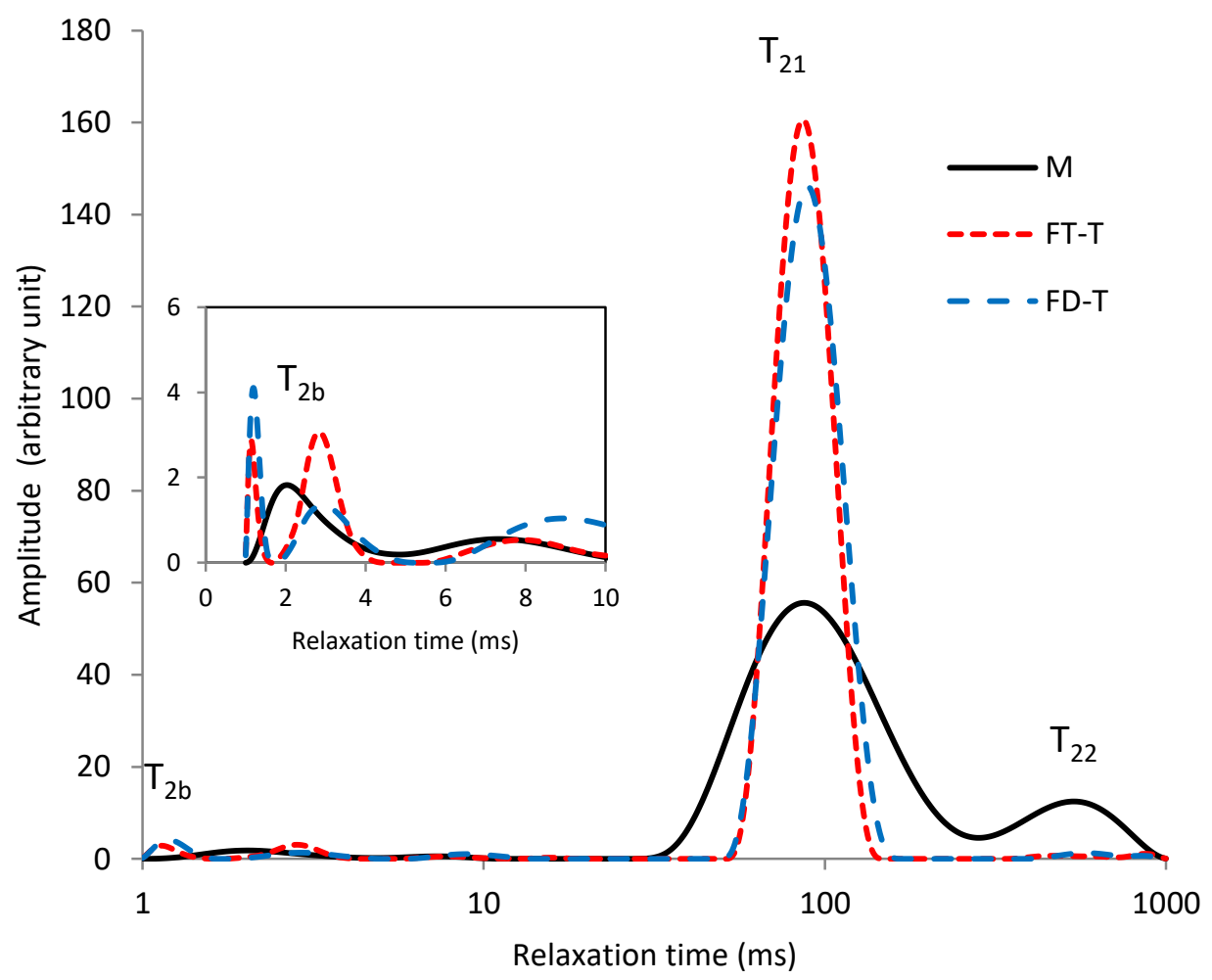

Figure 4 

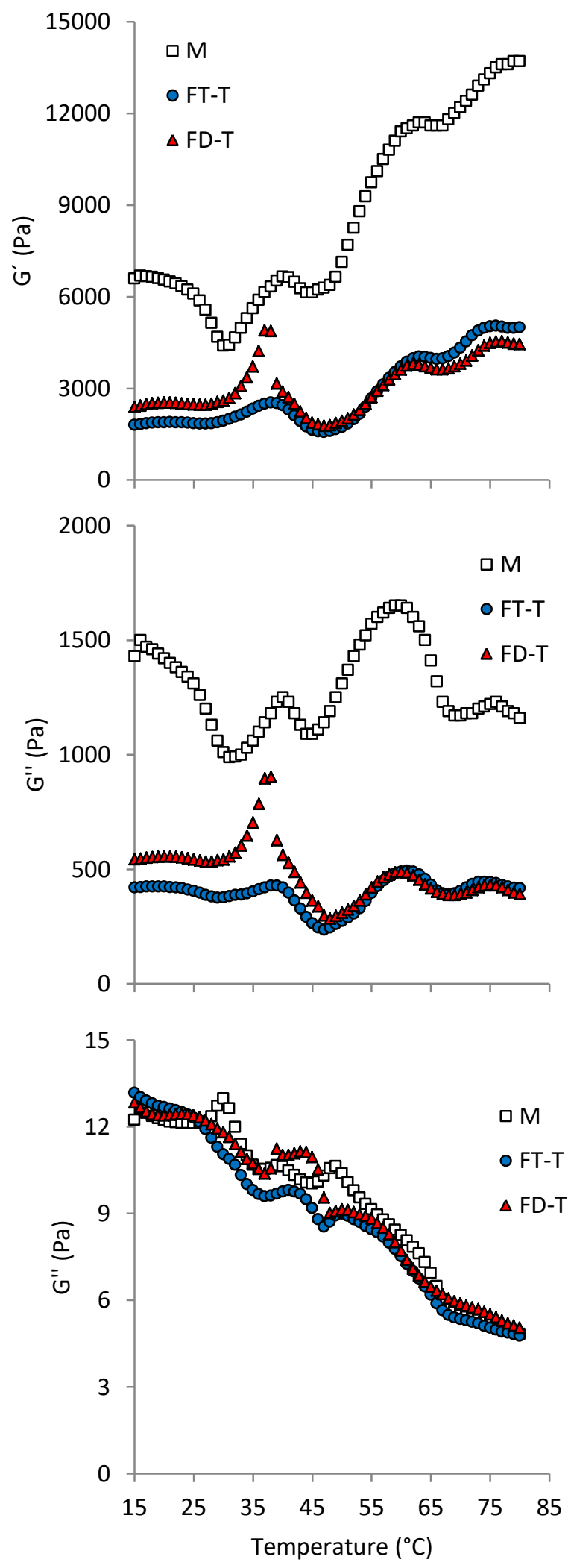

Figure 5 


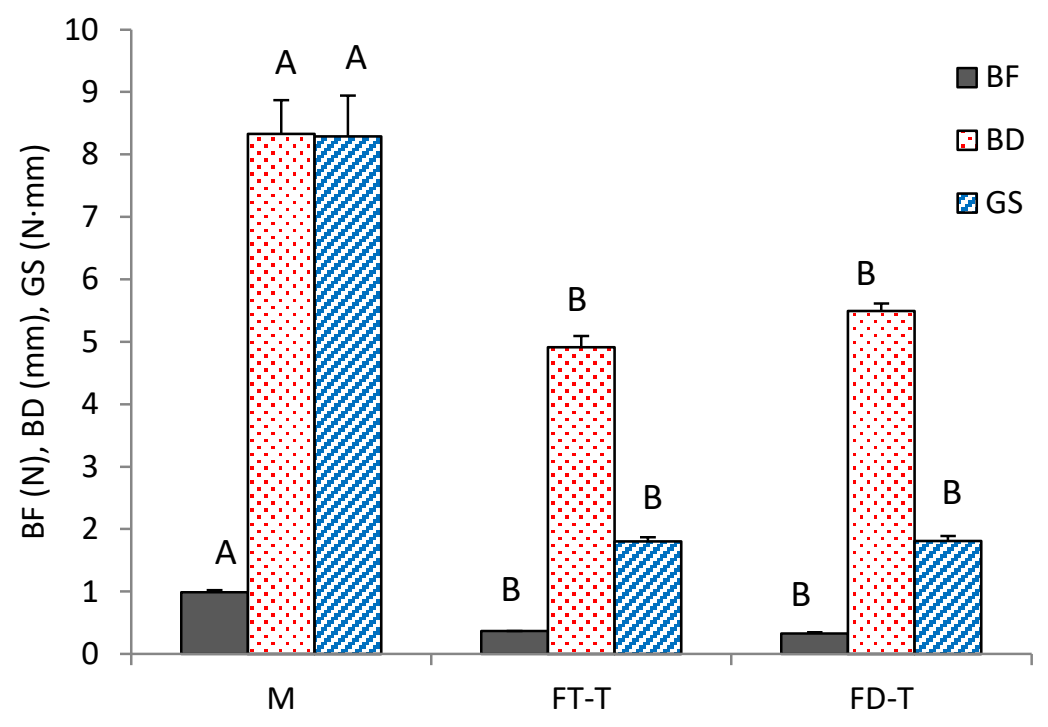

Figure 6 
TABLE 1. Z-average, polydispersity, zeta potential, moisture and water solubility of liposomes: L (Fresh), FT-T (Freeze-thawed with trehalose), FD-G (Freeze-dried with trehalose).

\begin{tabular}{c|ccccc}
\hline & $\begin{array}{c}\text { Z-average } \\
(\mathrm{nm})\end{array}$ & $\begin{array}{c}\text { Polydispersity } \\
(\mathrm{PDI})\end{array}$ & $\begin{array}{c}\text { Zeta potential } \\
(\mathrm{mV})\end{array}$ & $\begin{array}{c}\text { Moisture } \\
(\%)\end{array}$ & $\begin{array}{c}\text { Solubility } \\
(\%)\end{array}$ \\
\hline L & $141.3 \pm 1.9^{\mathrm{A}}$ & $0.225 \pm 0.003^{\mathrm{A}}$ & $-44.8 \pm 1.8^{\mathrm{A}}$ & $93,03 \pm 0.01^{\mathrm{A}}$ & $\approx 100^{\mathrm{A}}$ \\
FT-T & $219.7 \pm 7.7^{\mathrm{B}}$ & $0.277 \pm 0.030^{\mathrm{B}}$ & $-45.8 \pm 2.9^{\mathrm{A}}$ & $91.6 \pm 0.05^{\mathrm{B}}$ & $94.51 \pm 4.90^{\mathrm{B}}$ \\
FD-T & $210.0 \pm 3.5^{\mathrm{B}}$ & $0.303 \pm 0.027^{\mathrm{B}}$ & $-47.3 \pm 3.1^{\mathrm{A}}$ & $1.53 \pm 0.31^{\mathrm{C}}$ & $97.15 \pm 1.17^{\mathrm{B}}$ \\
\hline
\end{tabular}

Different letters $(A, B, C, D, E)$ indicate significance differences $(p \leq 0.05)$ among samples for each parameter. 
TABLE 2. Moisture, Salt-soluble protein and Water holding capacity (WHC) of salt-ground muscle (M) with added liposomes: FT-T (Freeze-thawed with trehalose), FD-T (Freeze-dried with trehalose).

\begin{tabular}{c|ccc}
\hline & $\begin{array}{c}\text { Moisture } \\
(\%)\end{array}$ & $\begin{array}{c}\text { Salt-Soluble Protein } \\
(\%)\end{array}$ & $\begin{array}{c}\text { WHC } \\
(\%)\end{array}$ \\
\hline $\mathrm{M}$ & $85.11 \pm 0.13^{\mathrm{A}}$ & $72.73 \pm 2.63^{\mathrm{A}}$ & $57.26 \pm 2.44^{\mathrm{A}}$ \\
FT-T & $82.21 \pm 0.16^{\mathrm{B}}$ & $49.17 \pm 3.85^{\mathrm{B}}$ & $90.27 \pm 1.86^{\mathrm{B}}$ \\
FD-T & $82.77 \pm 0.07^{\mathrm{C}}$ & $37.47 \pm 0.07^{\mathrm{C}}$ & $85.88 \pm 1.73^{\mathrm{B}}$ \\
\hline
\end{tabular}

Different letters (A, B, C, D, E, F) indicate significance differences $(p \leq 0.05)$ among samples for each parameter. 
TABLE 3. Viscoelastic parameters of salt-ground muscle (M) with added liposomes: FT-T (Freeze-thawed with trehalose), FD-T (Freeze-dried with trehalose).

\begin{tabular}{c|cccc}
\hline & $\begin{array}{c}\mathrm{G}^{\prime}{ }_{1 \mathrm{~Hz}} \\
(\mathrm{~Pa})\end{array}$ & $\mathrm{n}^{\prime}$ & $\begin{array}{c}\mathrm{G}^{\prime \prime}{ }_{1 \mathrm{~Hz}} \\
(\mathrm{~Pa})\end{array}$ & $\delta_{1 \mathrm{~Hz}}$ \\
\hline $\mathrm{M}$ & $2034.3 \pm 138.2^{\mathrm{A}}$ & $0.16 \pm 0.01^{\mathrm{A}}$ & $373.23 \pm 16.32^{\mathrm{A}}$ & $10.40 \pm 0.27^{\mathrm{A}}$ \\
$\mathrm{FT}-\mathrm{T}$ & $2655.7 \pm 44.4^{\mathrm{AB}}$ & $0.185 \pm 0.00^{\mathrm{B}}$ & $561.57 \pm 7.20^{\mathrm{B}}$ & $11.90 \pm 0.06^{\mathrm{B}}$ \\
$\mathrm{FD}-\mathrm{T}$ & $3645.5 \pm 545.4^{\mathrm{B}}$ & $0.16 \pm 0.01^{\mathrm{A}}$ & $659.04 \pm 101.5^{\mathrm{B}}$ & $10.24 \pm 0.06^{\mathrm{A}}$ \\
\hline
\end{tabular}

Different letters $(A, B, C)$ indicate significance differences $(p \leq 0.05)$ among samples for each parameter. 